\title{
O TRABALHO DOCENTE NO BRASIL [década de 1950 aos dias atuais]: a precarização no contexto de (re)democratização
}

\author{
E. F. BORGES ${ }^{1, *}$, S. CECÍLIO ${ }^{2}$ \\ ${ }^{1}$ Instituto Federal de Educação, Ciência e Tecnologia do Triângulo Mineiro (IFTM), ${ }^{2}$ Universidade de Uberaba \\ elisabete_borges@uol.com.br*
}

Submetido 13/11/2017 - Aceito 10/10/2018

DOI: $10.15628 /$ holos.2018.6535

\begin{abstract}
RESUMO
Contextualizar o processo de transformação do trabalho docente no Brasil, em sua historicidade recente, constitui o foco principal nesse artigo. Partiuse do estudo sobre o trabalho docente nos meados do século XX, enfatizando os anos de 1990 ao início do século XXI. Nesse período, o trabalho docente passa por um processo progressivo de precarização decorrente das contradições ocorridas com a democratização e a expansão da educação básica e superior no Brasil. O objetivo é contribuir para um desenvolvimento profissional e uma atuação mais consciente e engajada dos profissionais da educação diante dos desafios que a sociedade apresenta. A metodologia consistiu na busca e seleção de material
\end{abstract}

\begin{abstract}
bibliográfico, por meio dos termos descritores: trabalho, pesquisa, tecnologia e inovação, tendo em vista a compreensão da realidade em movimento e contradição, a partir do materialismo histórico dialético. As reformas, com orientação tecnicista, empreendidas pelo Estado brasileiro não têm favorecido a superação do quadro de precarização geral vigente. $O$ impacto das pesquisas dos Programas de Pós-Graduação é pequeno diante do contexto de precariedade da educação no País. As considerações finais conduzem o leitor a refletir sobre a precarização atual do trabalho docente e a indagar sobre quais valores, práticas e atitudes cumpre desenvolver.
\end{abstract}

PALAVRAS-CHAVE: Trabalho Docente, Educação, Pesquisa, Tecnologia, Inovações.

\section{THE FACULTY WORK IN BRAZIL [decade of 1950 to current days]: the precarization in context of the (re)democratization}

\begin{abstract}
To contextualize the faculty work transformation process in Brazil, in its current historicity, constitutes the main focus of this article. From the study about the faculty work in the middle of the $20^{\text {th }}$ century, emphasizing the years from 1990 to the beginning of the $21^{\text {st }}$ century. In this period, the faculty work went through a progressive process of precarization due to the contradictions that happened with the democratization and the expansion of the basic and superior education in Brazil. The goal is to contribute for a more conscious and engaged professional development and performance by the education professionals in front of the challenges that the society presents. The methodology consisted in the search
\end{abstract}

and selection of bibliographical material, through descriptive terminology: work, research, technology and innovation, with a goal to comprehend the reality in movement and contradiction, from the dialectic historic materialism. The reforms, with technical orientation, employed by the Brazilian State hasn't favored the overcoming of the overall precarization picture in effect. The impact of the researches of the Post-graduation programs is small before the precarious context of the education in the country. The final consideration conducts the reader to reflect about the current precarization of the faculty work and to question about which values, practices and attitudes comply to develop

KEYWORDS: Facultywork, Education, Research, Technology, Inovation. 


\section{INTRODUÇÃO}

O início do século XXI está marcado, definitivamente, por mudanças profundas, para as quais o conhecimento científico e suas correspondentes inovações contribuíram de forma efetiva. O desenvolvimento científico e tecnológico, ao criar fronteiras inexploradas para a vida humana, também sinaliza novas necessidades e novas demandas, rapidamente incorporadas pela produção e pelo mercado. O cenário social contemporâneo é marcado por desigualdades culturais complexas e estamos diante de um futuro incerto. $\mathrm{O}$ acesso ao conhecimento tornou-se muito mais fácil, mas o fosso que se cria entre as pessoas que têm esse acesso e as que não têm tornou-se muito maior.

De fato, a sociedade passa por uma transformação paradigmática como nunca se viu antes, que pode ser traduzida pela mudança do modelo industrial para o modelo da sociedade da informação. Essa mudança de foco da sociedade industrial em relação à sociedade da informação conduz à rápida redefinição no modo de vida das pessoas, de tarefas a realizar, na reorganização das instituições e organizações que as executam, dentre outras, como a consolidação tecnológica, a comunicação instantânea e a automação industrial.

O impacto dessas mudanças ocorre em todos os segmentos da sociedade, uma vez que o contexto atual se constitui como um momento de crise generalizada, instabilidade econômica, decadência política, individualismo exacerbado e derrocada dos valores humanos. Desse modo, a humanidade vive um período de incertezas e de ausência de expectativas. O que está em jogo é a preservação de uma civilização que propicie alternativas reais de uma vida mais digna com a coparticipação de todos. A educação escolar pressupõe e envolve a relação entre um grupo mais experiente e outro mais jovem. Urge que se pense na direção desse processo compreendendo a formação social, moral, cognitiva e afetiva. Nesse processo, os professores é que vão assumir essa intermediação.

Na sociedade brasileira, nos últimos anos da segunda década do século XXI, em que pese uma considerável democratização do acesso à escola, o sistema educacional passa por críticas quanto aos seus resultados qualitativos e quantitativos. Embora várias alterações tenham ocorrido nas últimas décadas, o que se faz não atende às necessidades educacionais urgentes que a sociedade almeja. Dentre as explicações para a situação, podem ser ressaltadas as seguintes: problemas na gestão dos recursos, distanciamento entre políticas educacionais e sua implementação, condições de formação e de atuação profissional, política de apoio e incentivo à carreira docente. De um lado, há o argumento usual da falta de recursos e de outro, atribui-se aos profissionais a razão maior das deficiências apontadas.

Sem dúvida, uma educação de qualidade e de alcance populacional desejável requer a crença de que mais do que custos elevados, expressariam investimento e política de um país. Sem minimizar a necessidade do enfrentamento das deficiências educacionais brasileiras e enfatizar a importância da educação para uma sociedade menos desigual, é preciso analisar questões relativas ao trabalho docente. Nesse contexto de inovações tecnológicas e de desafios educacionais sem precedentes, procura-se contribuir para a explicação das relações necessárias, mas também contraditórias, entre o tipo de escolaridade adequada ao jovem do século XXI e o sistema produtivo e societário em intensa transformação. 
A contextualização do trabalho docente nas últimas sete décadas poderá contribuir para a reflexão sobre algumas alternativas postas para o professor diante das incertezas e desafios que a sociedade da era digital apresenta para a educação. As análises e considerações realizadas pretendem resgatar a historicidade do trabalho docente no Brasil, tendo como referência uma revisão da literatura e como base os termos descritores trabalho, pesquisa, tecnologia e inovação para buscar a compreensão da realidade em movimento e em contradição. Trata-se de estimular, conduzindo o leitor a indagar sobre quais valores, práticas e atitudes desenvolver no trabalho docente em face dos desafios postos pela realidade educacional.

\section{REVISÃO BIBLIOGRÁFICA}

O texto analisa o momento crítico atual e ressalta aspectos da transição entre a sociedade industrial e a sociedade da informação. As transformações são tão significativas que chegam a demarcar uma era, que tem recebido diferentes denominações. Há autores que a chamam de Terceira Revolução Industrial ou Revolução da Automação (Saviani, 2002a, p. 164). Sociedade da Informação e da Interdisciplinaridade (redes) é a denominação atribuída por Baumgarten, Teixeira e Lima (2007). A Agência Brasileira de Desenvolvimento Industrial (ABDI) admite que há segmento da sociedade brasileira como a indústria extrativa que se encontra na quarta Revolução Industrial, sobretudo, considerando a adoção de tecnologias avançadas, tais como: manufatura aditiva, inteligência artificial, internet das coisas, biologia sintética e sistemas ciberfísicos.

Nos últimos 50 anos, a revolução da informação ocorreu com o aparecimento, diversificação e aperfeiçoamento das tecnologias que possibilitam a recolha, o armazenamento, o compartilhamento, a transmissão, a análise e a apresentação de dados. Porém, como tudo que se considera revolucionário e capaz de alterar paradigmas e comportamentos, a transição trouxe benefícios e questionamentos sobre o sentido, alcances e as finalidades da informação que afetam a educação e conduzem a novos estudos sobre exigências e desafios emergentes.

Nesse sentido, autores como Saviani (2002a; 2002b) e Gatti (2009) contribuem com análises que permitem compreender os fundamentos teóricos da educação e suas intimas relações com o trabalho docente. Em outra vertente de análise, Charlot (2008) convida a revisitar o contexto histórico da educação brasileira recente para compreender o momento crítico pelo qual passa o sistema educacional atual. Já Ens, Gisi e Eyng (2011) discutem desafios relacionados à formação continuada, trabalho com a diversidade cultural no currículo, atuação com grupos étnicos, raciais, pessoas com deficiências, violência, bullying e indicam alternativas de enfrentamento para os mesmos discorrendo sobre os sentidos do trabalho docente, atividade essencialmente humana realizada com, sobre e para seres humanos.

Saviani (2002b) analisa a globalização do processo produtivo e do trabalho e a alternância dos momentos de crise, que segundo o autor é intencional e gerenciado pelos interesses da burguesia internacional que controla a política econômica mundial. Basso (1998) faz algumas reflexões sobre o trabalho docente nesse contexto de globalização e aponta a possibilidade do mesmo ocorrer com um nível de autonomia satisfatório. A formação do professor e o domínio 
das ferramentas básicas para o exercício da docência vão conferir condições para a realização de um trabalho mais autônomo.

Giroux (1999) e Zeichner (1998) apresentam alternativas para o enfrentamento da crise atual pela qual passa a educação brasileira indicando as propostas de um professor como um intelectual transformador e/ou como um professor pesquisador. E Dusavitskii (2014) propõe a construção de uma sociedade aberta para o século XXI baseada nos valores: liberdade individual e solidariedade, independência e cooperação voluntária.

Na perspectiva do materialismo dialético, Ciavatta (2015) tece considerações sobre as contradições e percalços da relação espaço-tempo. Ressalta ainda as opções teóricometodológicas, pesquisa, tecnologia e inovação como categorias que perpassam o trabalho em seu sentido ontológico. Para Ciavatta (2015, p. 59), a produção da existência não se limita aos bens materiais, mas abrange "ideias, representações, cultura, conhecimento, ciência, o que, em seus termos inovadores, significa a produção social da existência".

Antunes (2018) evidencia um novo tipo de trabalhador a que chama de infoproletário, que vive a experiência do trabalho polivalente, "pejotizado", flexível e intermitente, dadas as reestruturações produtivas do capitalismo global conjugadas ao avanço tecnológico e a consolidação da era digital. Reconhece Antunes (2018, p. 65):

\begin{abstract}
O mundo produtivo contemporâneo, particularmente a partir do amplo processo de reestruturação do capital desencadeado em escala global no início da década de 1970, vem apresentando um claro sentido multiforme. Por um lado, acentuando as tendências de informalização da força de trabalho em todo o mundo e de aumento dos níveis de precarização da classe trabalhadora. No outro lado do pêndulo, as tendências em curso nas últimas décadas estariam sinalizando traços que seriam vistos como mais "positivos" em direção a uma maior intelectualização do trabalho, sobretudo nos ramos dotados de grande impacto tecnológico-informacional-digital.
\end{abstract}

Flores (2018) argumenta sobre a importância do investimento em educação de modo a traduzir a centralidade que lhe é atribuída no discurso e, reforça a necessidade de maior atenção e visibilidade no espaço público. Entre outras vertentes, a autora propõe pensar o lugar da educação na sociedade atual.

É certo que a Educação constitui um esforço de todos (políticos, professores, pais, alunos, investigadores, etc.) pela sua importância decisiva na transformação da sociedade e no desenvolvimento das gerações futuras, mas importa perguntar qual é o verdadeiro valor da Educação? Até que ponto se Ihe atribui, na prática, o lugar de destaque que merece (sobretudo se a compararmos com outros temas)? (Flores, 2018).

Diante do contexto analisado, evidencia-se o fato de que as transformações são globais e geram demandas, conflitos e contradições nos diversos setores da sociedade e, em especial, na área educacional, desencadeando, dentre outros problemas, uma situação de aumento da vulnerabilidade no mundo do trabalho e de precariedade no trabalho docente. De um lado, há autores que analisam essas contradições para compreender melhor a situação caótica em que se encontra a educação. De outro lado, encontram-se autores que, diante dos desafios postos, reforçam a importância e o papel da educação no desenvolvimento individual e social.

\title{
METODOLOGIA
}


Com o propósito de realizar uma reflexão sobre o momento crítico que caracteriza a sociedade do final do século XX e início do século XXI optou-se por desenvolver uma pesquisa bibliográfica cujas fontes utilizadas foram concentradas em textos, artigos e livros focados no tema: trabalho docente - desafios contemporâneos, em uma perspectiva dialética materialista histórica. A seleção dos textos analisados foi desencadeada pelos debates e discussões desenvolvidos durante as aulas e atividades desenvolvidas na disciplina Epistemologia e Pesquisa em Educação do Programa de Pós-Graduação em Educação da Universidade de Uberaba, no primeiro semestre de 2017. A metodologia proposta pela professora Cecílio (2017) motivou a elaboração deste artigo:

Do particular ao geral, ou do geral ao particular, e no diálogo com a realidade e as interpretações dela possíveis, sistematizadas na forma de produção teórica - livros, artigos, entrevistas - tomando como diretrizes a observação e a leitura do universo individual e coletivo, integrarão a dinâmica do curso, as seguintes atividades: gv/go; oficina, aulas dialogadas, palestras e/ou mesa-redonda e entrevistas, discussão da bibliografia com base em questões e roteiros específicos, oficina para análise de projetos (Cecílio, 2017, p. 2).

Os textos selecionados foram trabalhados nas disciplinas obrigatória e optativas cursadas durante o primeiro semestre de 2017, e abordam o tema, cujo enfoque se constituiu no referencial teórico para as análises sobre as transformações ocorridas no trabalho docente na perspectiva social, econômica, cultural e política da sociedade brasileira, no período já apontado. A reflexão metodológica orientou-se pela visão que busca explicar o processo de transformação do trabalho docente no Brasil, em sua historicidade recente, relacionando-a à conjuntura a que se liga, e ao mesmo tempo, discutindo como ela é condicionada pelas dimensões que a compõem.

Na segunda metade do século XX em diante, há um processo intenso de urbanização, e simultaneamente ocorre a democratização e expansão das oportunidades educacionais, inicialmente, em relação à educação básica e, posteriormente, estendidas ao ensino superior. 0 rápido processo de urbanização da sociedade brasileira desencadeia mudanças profundas que alteram a vida das pessoas que viviam na zona rural e passam a viver nas cidades. Daí, o recorte da análise centrada nos últimos setenta anos, período marcado por essa alteração do rural em relação ao urbano. Essa mudança do estilo de vida rural para o urbano afeta diretamente a instituição escolar que passa a abarcar uma maior demanda e o trabalho docente que corre o risco de se expor a uma massificação com consequências para docentes e discentes e para o processo ensino-aprendizagem.

Assim, a análise do período em destaque caracteriza o trabalho docente inserido no contexto socioeconômico, político e cultural e as suas inter-relações com o sistema educacional, identificando as contradições geradas pelas mudanças ocorridas e ainda presentes no cotidiano do trabalho docente. Para melhor delineamento da metodologia da busca de material sobre o trabalho docente foram utilizados os termos descritores: trabalho, pesquisa, tecnologia e inovação. Essas opções de busca a partir de termos descritores, enquanto também constructos intelectuais, colaboraram no esforço de apreensão do movimento da realidade e identificação das contradições que afetam de modo particular os profissionais da educação, à medida que 
viabilizaram a aproximação da teoria com os fatos. Elas perpassam e compõem o trabalho docente e, por isso, potencializam uma melhor análise e compreensão.

À opção de busca pelos termos descritores somou-se uma escolha epistemológica. Os critérios para a escolha das correntes histórico-filosóficas positivismo e materialismo dialético histórico abordadas sucintamente se deveram ao fato do positivismo ter prevalecido durante os séculos XIX e XX e, ainda, ser uma opção em diversos segmentos do conhecimento, especialmente no campo das exatas e da saúde, em especial nos cursos que preparam os profissionais para atuar nas referidas áreas. Quanto à opção pelo materialismo dialético histórico como recurso para entender e explicar os fenômenos sociais, ela se deu por compreender que "parte da produção social da vida humana em sociedade e contextualizada historicamente" (Marx, 1979 como citado em Ciavatta, 2015, p. 23), favorece a leitura de complexas relações entre as partes e a totalidade e suas implicações na causalidade e expressões dos acontecimentos sociais. Assim considerando, o estudo do trabalho docente como expressão de uma relação social que se produz em determinado espaço-tempo e apresenta desafios a serem interpretados e enfrentados na atualidade, pode ter recuperada sua dimensão histórica e social, a partir da referida opção de abordagem, pelo que permite tratar das relações entre trabalho docente e educação e em relação a elas desenvolver as ações pertinentes e necessárias.

É consenso de que a formação de professores e o trabalho docente são importantes para uma educação de qualidade e o objeto de estudo selecionado para reflexão constitui o cerne dessa relação. Por isso, pretende-se aqui contribuir para um desenvolvimento profissional e uma atuação mais consciente e engajada dos profissionais da educação diante dos desafios que a atual sociedade da informação apresenta a esses e outros profissionais na atualidade.

\section{DESAFIOS E CONTRADIÇÕES DO TRABALHO DOCENTE NA CONTEMPORANEIDADE}

Para o trato do tema em questão, procurou-se destacar as ideias principais de autores escolhidos para a leitura sobre a docência procurando estabelecer consensos e aspectos próprios de cada autor. Assim, Charlot (2008) propõe uma reflexão partindo de uma leitura histórica do contexto da instituição escolar brasileira para situar como e o porquê chegou a um estágio de profundas contradições, chegando a perder de vista o seu foco principal. A cada nova atribuição que a escola assume maior é a redução do tempo e do espaço para a realização de sua função específica.

Para compreender as injunções sociais do tempo presente e as contradições que permeiam o trabalho docente, cabe remeter sua condição ao contexto histórico da condição do professor brasileiro nas últimas décadas, em especial das últimas sete décadas. Assim, a década dos anos 1950 era de relativa estagnação econômica sem grandes possibilidades de mobilidade social. O modelo econômico era agrário exportador. Predominava a atividade rural. A educação não se constituía em instrumento de alteração do status social e, por isso, era aceita com tranquilidade. Os professores eram mal pagos, mas respeitados. A metodologia de ensino era a tradicional e a função da escola básica era clara e bem definida: alfabetizar, e os professores a realizavam com qualidade e competência. 
Entre as décadas de 1960 e 1970 acentua-se um processo de desenvolvimento socioeconômico que já vinha acontecendo na sociedade brasileira e que autores como Manfredi (2003, p. 95) analisa como substituição do modelo agroexportador pelo modelo de industrialização. Toda a mudança tem seu germe em período anterior, mesmo que não de modo explícito. Esse modelo começa a ser esboçado ainda na década de 1930. Em decorrência da crise mundial da economia capitalista, o Brasil passa pela necessidade de produzir as manufaturas que importava até aquele momento. A crença sobre a natural vocação agrícola do Brasil passa a ser questionada e surge a industrialização como uma nova bandeira em torno da qual se unem as diferentes forças sociais. Esse processo vai culminar no início da década de 1960.

A industrialização traz no seu bojo o processo de urbanização e a progressiva penetração de investimentos externos. Há uma mobilidade intensa da população do campo para a cidade. Nesse contexto, a escola passa a ter uma importância fundamental para a população urbana que necessitará da educação básica para ocupar os postos de trabalho que vão surgindo com o processo de industrialização. A partir da metade da década de 1960, o governo militar visava principalmente o desenvolvimento econômico com segurança.

Diante desse objetivo, a baixa produtividade do sistema de ensino, identificada no reduzido
índice de atendimento da população em idade escolar e nos altos índices de evasão e
repetência, era considerado um entrave que necessitava ser removido. A adoção do modelo
econômico associado-dependente, a um tempo consequência e reforço da presença das
empresas internacionais, estreitou os laços do Brasil com os Estados Unidos (Saviani, 2013, p.
367).

Para atender à demanda de preparação de mão de obra para essas empresas internacionais e a meta de elevação geral da produtividade do sistema escolar, a escola começa a ser pensada nessa perspectiva do desenvolvimento econômico e social. É atribuído a ela um papel fundamental nesse processo, porque o fato de ser escolarizado transforma-se em prérequisito para o ingresso no mercado de trabalho. A população busca a instituição escolar agora como uma possibilidade real de ascensão social e os governos respondem a essa aspiração promovendo a expansão em grande escala das instituições escolares.

Todavia, nesse novo contexto, os professores passam a ser pressionados e sua prática começa a ser questionada. O sucesso escolar é a condição de ingresso nos postos de trabalho e, por isso, ele é importante para os alunos e suas famílias e quando não ocorre a "culpa" é do professor que não ensinou bem, está "perseguindo" o aluno, dentre outras representações sociais. Começam as injunções sociais e vai constituir-se no primeiro impacto na profissão do professor.

O processo de expansão acelerada da educação básica vai ocorrer à custa de muita improvisação dos ambientes de trabalho, da formação aligeirada dos professores ou, até mesmo, a improvisação desses profissionais. Por outro lado, além de ir para a escola os bons alunos, vão também aqueles que, pressionados pela família e pelo novo contexto social, passam a frequentar a instituição, mesmo sem o interesse necessário para passar pelo processo de escolarização. Nesse quadro, acentua-se o processo de precarização do trabalho docente que decorre dos baixos salários, das condições inadequadas das escolas e da própria democratização das oportunidades educacionais traduzida pela grande expansão do ensino fundamental. 
Nas décadas de 1980 e 1990, outra ruptura ocorre no desenvolvimento sócio- econômico da sociedade brasileira, a partir do avanço da globalização. Fatores como eficácia e qualidade, lei do mercado, desenvolvimento das Tecnologias de Informação e Comunicação (TIC) acarretam um impacto social e econômico significativo. Neste sentido, para atender aos desafios colocados pelas mudanças socioeconômicas ocorridas, torna-se necessário cursar o ensino superior. Mais uma vez o poder público e também a iniciativa privada são exigidos a responder aos anseios sociais, iniciando-se então o processo de expansão do ensino superior que, até aquele momento, encontrava-se concentrado nas capitais e grandes centros e, a partir de então, passa a se dar também nas cidades do interior.

A pressão e as cobranças constantes aumentam e desestabilizam ainda mais o professor. Há uma valorização dos resultados expressos em notas que passa a ser o foco dos alunos, das famílias e, até mesmo, dos professores, em detrimento do processo ensino e aprendizagem que fica secundarizado. Esse fato vai desencadear uma série de desajustes na função da escola e do professor que perdem o foco de sua especificidade para adequar-se a um contexto no mínimo equivocado e contraditório, pois conforme traduz Charlot (2008, p. 21): “o professor sonha em transmitir saberes e formar jovens, mas vive dando notas a alunos". Nesse contexto econômico, social e cultural de profundas e rápidas mudanças há uma reconfiguração sócio escolar permeada de contradições. Essas contradições resultam de tensões internas provocadas pela prática docente na condução do processo ensino e aprendizagem, pela organização e o funcionamento da instituição escolar e, também, pelas expectativas que a sociedade espera e impõe à escola.

As contradições identificadas por Charlot (2008) tecem um panorama que constitui um convite para repensar a educação na sociedade brasileira. A dualidade entre o professor herói ou vítima coloca em xeque a figura idealizada pela pedagogia do profissional amoroso, vocacionado para realizar uma missão. De outro lado, a vitimização do professor decorre de uma realidade de baixos salários, condições inadequadas de trabalho, quando o principal passa a ser a luta pela sobrevivência profissional e psicológica para depois pensar na formação dos alunos. Outra contradição refere-se à "culpa". Ela é de quem? Do professor ou do aluno? O processo ensino e aprendizagem envolve o professor no seu ato de ensinar e o aluno e a sua opção por aprender ou não. Portanto, é um processo de compromisso mútuo. O sucesso depende de ambos e a aprendizagem implica uma mobilização intelectual, afetiva, social e cultural do aluno.

Outra contradição apontada por Charlot (2008) diz respeito à orientação pedagógica adotada pela escola: tradicional ou construtivista? Muitos professores, ainda, adotam posturas e metodologias tradicionais, embora discursem sobre a opção que estiver em voga. Durante algum tempo esse discurso era pelo construtivismo. Universalista ou de respeito às diferenças? A instituição escolar é essencialmente universalista, porque a sua especificidade é divulgar saberes universais e sistematizados. Mas na escola atual, o professor deve respeitar as diferenças. $\mathrm{O}$ que seriam essas diferenças? Culturais? Étnicas? Fica aqui a indagação. Restaurar a autoridade ou amar os alunos? O processo educacional pressupõe autoridade e disciplina. A escola é um lugar específico, mas admite-se que no Brasil seja válido pensar em termos das relações com a comunidade enquanto local de resistência, de memória e de dignidade. Na perspectiva das contradições identificadas, Charlot (2008) considera o professor, no Brasil, como um "profissional da contradição". 
Inseridos em um contexto social contraditório, os professores incorporam essas contradições, que impõem limites sociais, culturais, econômicos e políticos, e são traduzidas nas falas, experiências e expressas no modo de ser e relacionar-se nos diferentes grupos sociais dos quais participam. As contradições são sociais e incorporadas pelos sujeitos que as expressam como resultado de sua subjetividade. Nesse início de século, as contradições parecem acentuarse cada vez mais. As profundas desigualdades socioculturais e os desafios futuros colocam enormes responsabilidades para os profissionais que vão intermediar o processo de transmissão cultural geracional, em especial realizado pelos professores. Qual é o foco que precisa estar claro nesse processo? Formação social, moral, cognitiva, afetiva contextualizada em um momento de crises profundas sociais, políticas, econômicas e culturais.

Diante da perplexidade que o momento atual apresenta aos profissionais da área e à sociedade como um todo, importa a consciência crítica para pensar e buscar soluções referentes à formação profissional, às condições de trabalho e à carreira docente como processos básicos da configuração identitária e profissional do professor. Para tal, a análise de Gatti (2009) é útil. Ela propõe cinco pressupostos para esse processo: que o fato educacional é cultural; que o papel do professor é absolutamente central; que o núcleo do processo educativo é a formação do aluno; que é preciso considerar a heterogeneidade cultural e social de professores e alunos; que as práticas educativas institucionalizadas determinam em grande parte a formação de professores e, na sequência, de seus alunos.

Esse processo de desenvolvimento e trabalho docente está inserido em um cenário social de profundas desigualdades culturais e assiste à transição de uma sociedade industrial para uma sociedade da informação. Esse fato determina mudanças múltiplas nas relações culturais. Há um processo de precarização das condições de vida e de trabalho que tende a se generalizar. A exploração aumenta de forma violenta e a possibilidade de uma vida digna e justa é cada vez mais precária (Gatti, 2009).

Com a revolução industrial ocorreu a transferência de funções manuais para as máquinas, substituindo-se cada vez mais o trabalho vivo pelo trabalho morto. Atualmente, o que está ocorrendo é a transferência das próprias operações intelectuais para as máquinas. Daí a denominação de "era das máquinas inteligentes" (Saviani, 2002a). O processo produtivo está a exigir a universalização de uma escola unitária que desenvolva a personalidade dos educandos no máximo de suas potencialidades, conduzindo-os ao desabrochar pleno de suas faculdades afetivas, emocionais, espirituais e intelectuais, assim como as habilidades, competências, práticas, etc. O que importa nesse novo contexto produtivo é uma formação geral sólida, a capacidade de manejar conceitos e o desenvolvimento do pensamento abstrato. Todavia, isso não ocorre para a maioria da população que encontra barreiras colocadas pelas relações sociais vigentes que impedem a generalização da produção baseada na incorporação maciça das tecnologias avançadas (Saviani, 2002a, p. 164).

A não implantação das tecnologias avançadas de forma generalizada no modo de produção do país também inviabiliza e 'dispensa' a expansão de um sistema escolar com uma sólida educação geral necessária para operar no contexto da sociedade da informação. Como o acesso a esse tipo de formação e de atuação fica cada vez mais restrito, o abismo que se cria 
entre esses e os que não têm acesso à informação é cada vez mais profundo, aumentando as desigualdades sociais, culturais e econômicas.

\begin{abstract}
Assim, de premissa objetiva para a libertação geral da humanidade do jugo das necessidades materiais, o avanço tecnológico converte-se, sob as relações sociais de produção capitalista, em instrumento de maximização da exploração da força de trabalho, ampliando a marginalização social através do crescente desemprego mantido sob controle (Saviani, 2002b, p. 21).
\end{abstract}

O desemprego torna-se em um dos elementos do processo de controle das crises. Quando ocorre o desaquecimento da economia, ele funciona como forma de ajuste das relações sociais vigentes, sob o comando dos interesses do sistema financeiro internacional. Nesse contexto, a educação é colocada a serviço dos interesses capitalistas, em uma concepção denominada de "produtivista de educação". Essa concepção começou a ser engendrada no Brasil a partir da década de 1950 respondendo às necessidades de planificação da economia e dos sistemas de ensino. Nessa ótica, os investimentos feitos na área educacional mudam de patamar, uma vez que ela deixa de ser um bem de consumo para tornar-se um bem de produção dotada de um valor econômico, que ainda domina o cenário nesse início do século XXI (Saviani, 2013).

A formação de grupos gerenciadores de instituições educacionais que obtêm lucros cada vez maiores, nessa área, é uma tendência. Atualmente, há grupos que constituem verdadeiros conglomerados educacionais, como o Kroton, Anhanguera, Estácio e Anima, considerados empresas de capital aberto, conforme formulários de referência apresentados à Comissão de Valores Mobiliários (CVM) pelas companhias. O porcentual de universitários desses conglomerados passou de 12,8\% para 27,8\% do total, entre 2010 e 2014. O Programa de Financiamento Estudantil (Fies) do governo federal acompanhou essa expansão. No mesmo período, o montante de recursos públicos reservado para instituições privadas saltou de $\mathrm{R} \$ \mathbf{8 8 0 , 3}$ milhões por ano para $\mathrm{R} \$ 13,7$ bilhões, alta de $1.456 \%$. Os dados foram compilados por estudo do Observatório do Ensino do Direito da Fundação Getúlio Vargas (FGV). A pesquisa mostra que são 2,1 milhões de alunos nesses grupos. Eles já superam as matrículas da rede pública, que tem $25,1 \%$ do total.

Desta forma, os dispêndios com educação passaram a ser considerados desejáveis, não apenas por razões sociais ou culturais, mas especificamente por motivos econômicos, e transformam-se num investimento de retorno ainda mais compensador do que outros tipos de investimentos ligados à produção material (Saviani, 2002b, p. 22).

A questão que se coloca é a de que existe um processo intencional de administração das crises. Há uma alternância controlada pela política econômica mundial entre períodos de crescimento e de recessão ou combina recessão em alguns países e crescimento em outros. Dessa forma, a burguesia internacional controla a situação e neutraliza as pressões dos trabalhadores. Esta é uma "relevante transformação do capitalismo que afetou decisivamente o mundo do trabalho e a educação na segunda metade do século $X X$, mantendo-se presente no princípio do século XXI" (Saviani, 2002b, p. 24).

Pesquisas realizadas recentemente revelam a precariedade atual do trabalho docente. Uma dessas pesquisas, realizada por Silva e Silva (2017), sobre avaliação de políticas públicas, revela resultados que confirma a exploração do trabalhador no atual estágio da globalização econômica. A investigação ocorreu sobre o processo de implementação do ensino médio 
integrado em escolas técnicas estaduais da rede de ensino de Pernambuco e as condições de trabalho docente. $O$ estudo possibilitou a constatação de que o aumento da jornada escolar vem acontecendo com a intensificação do trabalho docente que decorre da pressão por resultados e da perspectiva gerencial adotada.

Nas experiências analisadas, a ênfase no reforço escolar, a intensificação do tempo de trabalho e do estudo em sala de aula e o sentimento de encarceramento de docentes e discentes significam um processo de precarização do trabalho docente e da própria escola (Silva \& Silva, 2017, p. 238).

No artigo Cadernetas de saúde e trabalho diário de professores de universidades públicas", Souza (2018) usou como instrumento de pesquisa: as "cadernetas de saúde e trabalho" com oito professores de uma instituição federal de ensino superior (IFES), localizada no Rio de Janeiro. Esse instrumento propicia ao participante da pesquisa um papel de protagonista. Para o tratamento dos dados foi usada a técnica de análise temática, que possibilitou agrupar o material empírico em quatro categorias principais de discussão: o tempo de trabalho e as múltiplas atividades de trabalho do professor; precarização das condições de trabalho em universidades; saúde docente entre limites e cadernetas sob o olhar dos seus autores. Como conclusão do estudo, o autor ressalta o tema alusivo à sobrecarga de trabalho e pressão para cumprimento de metas. O instrumento utilizado "cadernetas de saúde e trabalho" mostrou-se "como ferramenta de pesquisa com potencial para se gerar conhecimento em perspectiva coletiva" (Souza, 2018).

Em "Fundamentos teóricos e metodológicos da precarização do trabalho docente", Macedo e Lima (2017) analisam o processo de intensificação da precarização do trabalho docente no Brasil, a partir dos anos de 1990. Segundo as autoras essa situação de precariedade decorre da adoção de novos modelos de gestão educacional pautados nos princípios da "Nova Gestão Pública". Com orientações de organismos internacionais foram efetivadas reformas educacionais e modelos de formação que contribuem, ainda mais, para acentuar a situação de precariedade do trabalho docente, e afastar a perspectiva da educação para a emancipação humana.

$\mathrm{O}$ trabalho docente insere-se nesse contexto globalizado do trabalho e do trabalhador e pressupõe a análise das suas condições subjetivas e objetivas. $\mathrm{O}$ aspecto subjetivo refere-se à atividade consciente do homem no seu modo de planejar a sua ação com maior ou menor autonomia dependendo das condições objetivas, entendidas como as situações efetivas de seu trabalho. As condições objetivas compreendem a organização escolar e curricular, a situação pedagógica, o planejamento das práticas e das aulas, e inclui, ainda, a remuneração do professor.

As transformações ocorridas nas condições de trabalho docente estão vinculadas às mudanças das formas capitalistas de produção. Todavia, a especificidade do trabalho escolar mantém a autonomia do professor na seleção de metodologias, de conteúdos e de atividades para serem desenvolvidas junto aos alunos. Essa natureza do trabalho docente dificulta o controle sobre o mesmo, que pode ocorrer muito mais pela formação aligeirada do professor do que por outras vias como as secretarias, o Estado e/ou ações de especialistas (Basso, 1998).

Nessa perspectiva, vão surgindo várias propostas de atuação para o professor que se vê nesse contexto de precarização das condições de trabalho e de formação diante de um futuro 
sem muitas perspectivas, mas com possibilidades reais para um trabalho autônomo. Para melhor exame das condições do trabalho docente e o papel do professor na atualidade, as propostas de Giroux (1999) e de Zeichner (1998) apontam caminhos. Tanto a proposta de um professor como um intelectual transformador ou como um professor pesquisador parecem alternativas válidas para o enfrentamento da crise pela qual passa a educação brasileira.

Zeichner (1998) convida o leitor para entrar nas tramas do poder, do privilégio, da voz e do status na pesquisa educacional. E no decorrer de suas argumentações, ele vai tecendo as polaridades que ocorrem entre o professor pesquisador e o professor acadêmico. Enquanto esse último, em número expressivo, constrói a sua carreira com projetos de pesquisas cada vez mais abstratos e distantes da realidade, com uma linguagem compreensiva apenas pelos seus pares, focando o lado negativo do trabalho desenvolvido pela escola e pelos professores que nela atuam, para garantir a sua carreira e o seu status medido com as publicações em periódicos de renome ou com a entrega dos relatórios de pesquisa nas agências de fomento, com pouco engajamento nas questões sociais e pedagógicas, os professores tentam realizar o seu trabalho respondendo às questões do cotidiano escolar, sem condições de uma prática sistemática mais científica. É a nítida separação entre discurso e ação; teoria e prática; apesar de alguns trabalhos com o uso de TIC seja um misto de manual e intelectual, como pode sê-lo o caso do trabalhador dos setores de informática e o de muitos professores.

Todavia, Zeichner (1998) aponta algumas alternativas para superar essa divisão entre os pesquisadores acadêmicos e os professores pesquisadores a partir de uma reestruturação da relação social, política e econômica da produção de conhecimento em pesquisa educacional. Ele relata histórias e experiências positivas nesse intercâmbio entre pesquisadores acadêmicos e professores pesquisadores, e propõe, nesse processo de superação das divisões que existem entre esses profissionais, o compromisso de ambos na busca da promoção de todos os estudantes a uma forma de vida mais decente e significativa. Para isso, faz-se necessária a discussão do significado da relevância da pesquisa, o desenvolvimento de um tipo de colaboração, de fato, genuína e de dar suporte aos professores na realização de pesquisa e no acolhimento dos resultados.

Para Giroux (1999), a proposta de professores como intelectuais transformadores ocorre em um processo de reflexão e prática acadêmica a serviço da educação e tem como pressuposto básico tornar o pedagógico mais político e tornar o político mais pedagógico. Para isso, é fundamental a união da linguagem crítica com a linguagem das possibilidades.

$\mathrm{Na}$ atualidade, essas reflexões levam a indagar no trabalho docente que relação pedagógica mudar ou enfatizar? Quais valores, práticas e atitudes desenvolver? Qual estrutura formativa responde a esse turbilhão de incertezas? Que conteúdos e didáticas contemplar em qual inserção política e social? Ficam aí as indagações como desafio que precisam ser enfrentados no contexto do trabalho docente nessa sociedade em mudança.

Em prosseguimento do balanço dos estudos sobre o trabalho docente, uma pesquisa realizada com estudantes do curso de pedagogia vai reforçar a visão da atividade docente em uma perspectiva idealizada (Ens, Gisi \& Eyng, 2011). Há uma identificação do professor como alguém vocacionado traduzindo sempre uma imagem idealizada que não necessita passar por um 
processo de profissionalização diferentemente de outras atividades profissionais. O grupo pesquisado apontou como função central dos pedagogos a docência, ignorando a gestão e a pesquisa e estabeleceu uma relação acentuada com as políticas de formação de professores. Há uma forte relação da profissão com o gênero feminino nas justificativas dos baixos salários. Essas representações sociais da atividade docente traduzem concepções culturais, crenças e valores presentes no imaginário da sociedade brasileira. Feita essas considerações,

[...] podem ser visualizados, assim, dois aspectos importantes nas representações sobre a Pedagogia: um que se refere à identidade profissional, cujas diretrizes deixam evidente ser a docência a sua função principal; e outro que se refere às condições para exercer a profissão, cujos problemas continuam presentes. O fortalecimento da profissão envolve políticas educacionais que priorizem a educação no País e que dizem respeito, em especial, à valorização do trabalho docente. (Ens, Gisi \& Eyng, 2011, p. 314).

É necessário ressaltar que o trabalho docente se caracteriza também como uma atividade de interações humanas. E nesse sentido, ele tem uma dimensão emancipadora. Pode-se dizer que por meio do trabalho o homem se relaciona com a natureza, com o seu entorno, com a sociedade, para transformá-los e ajustá-los às suas necessidades e interesses. $O$ trabalho docente ao ser

[...] concebido como uma unidade é considerado em sua totalidade que não se reduz à soma das partes, mas sim em suas relações essenciais, em seus elementos articulados, responsáveis pela sua natureza, sua produção e seu desenvolvimento. A análise do trabalho docente, assim compreendido, pressupõe o exame das relações entre as condições subjetivas - formação do professor - e as condições objetivas, entendidas como as condições efetivas de trabalho, englobando desde a organização da prática participação no planejamento escolar, preparação de aula etc. - até a remuneração do professor (Basso, 1998).

Embora no estudo realizado haja um destaque para a necessidade de profissionalização do professor, enfatizado pelas políticas públicas educacionais traduzidas em documentos que apontam nessa direção, o que se verifica, ainda,

[...] no que tange às representações das futuras professoras sobre a profissão, observouse, por um lado, a imagem de uma profissão idealizada no que se refere à sua finalidade e relevância social e, por outro, a percepção da desvalorização no que se refere à falta de reconhecimento do trabalho realizado (Ens, Gisi \& Eyng, 2011, p. 315).

Nesse contexto, Dusavitskii (2014) traz um pouco de utopia, apresentando uma proposta de construção de uma sociedade aberta para o século XXI baseada nos valores: liberdade individual e solidariedade, independência e cooperação voluntária. Para construir esse ideal, ele aponta como alternativa a concepção de educação desenvolvente focada no aperfeiçoamento da personalidade, do pensamento e da consciência. E apresenta os fundamentos que distinguem o sistema de educação desenvolvente de outras inovações pedagógicas que:

[...] é caracterizado por uma descrição integral do sistema de educação precisamente como um sistema de aprendizagem e educação. Ele é construído sobre bases filosóficas definidas: sobre a concepção marxista da atividade humana substantiva e, consequentemente, também sobre os princípios humanísticos da tradição filosófica e psicológica (Dusavitskii, 2014, p. 79).

É preciso ressaltar, ainda, que a mudança educacional depende basicamente das transformações que ocorrem na sala de aula. Todavia, nenhuma inovação ocorre se não perpassa o nível institucional. A mudança educacional depende dos professores e da sua formação, mas 
depende também da transformação das práticas pedagógicas na sala de aula. Hoje em dia nenhuma inovação ocorre se não envolver a mudança em nível das organizações escolares e do seu funcionamento. Por isso, falar de formação de professores implica necessariamente repensar o projeto de escola. As proposições educacionais ocorrem em domínios ou muito amplos, de macro sistema, incluindo as políticas educacionais nacionais ou internacionais ou em domínio demasiado restrito de micro sala de aula. A subjetividade do professor expressa essa síntese entre o macro e o microssistema no contexto educacional:

Cada uma das formas de expressão da subjetividade social expressa a síntese, em nível simbólico e de sentido subjetivo, do conjunto de aspectos objetivos, macro e micro, que se articulam no funcionamento social. [...] Em qualquer instituição, as pessoas compartilham, no interior do espaço social instituído, uma série de códigos explícitos e implícitos em suas diversas práticas sociais, as quais convertem em 'realidades' socialmente aceitas que só serão transformadas pela ação crítica e diferenciada dos sujeitos concretos que vivem nesta realidade (González Rey, 2005, p. 24-26).

Repensar a organização escolar surge como uma possibilidade de discussão de questões educativas pelo estabelecimento de pontes entre as definições do macrossistema e a especificidade da sala de aula. Todo o ambiente escolar deve formar e educar e os sujeitos (professores, funcionários, gerentes) devem ter o compromisso de construir esse ambiente. Assim, o trabalho do professor ultrapassa e muito o ambiente restrito da sala de aula que deve ter como princípio fundamental a cooperação. É uma nova territorialidade onde trabalhar e formar constitui-se em uma unidade e transforma a formação permanente em um processo contínuo integrado no dia-a-dia dos professores e das escolas.

São muitos os desafios que precisam ser enfrentados e, neste contexto, o profissional responsável por esse processo de formação de cidadãos é o professor, e a sua atuação surge de modo imperativo para que possa responder por essa atividade em uma sociedade em crise. Compreender esse contexto é fundamental para o trabalho docente. Todavia, a realidade social, como toda realidade, é infinita. Toda ciência implica opção e o olhar vai depender de qual ângulo científico ou até mesmo empírico cada 'realidade' está sendo analisada.

\footnotetext{
A epistemologia qualitativa defende o caráter construtivo interpretativo do conhecimento, o que de fato implica compreender o conhecimento como produção e não como apropriação linear de uma realidade que se nos apresenta. A realidade é um domínio infinito de campos inter-relacionados independentes de nossas práticas; no entanto, quando nos aproximamos desse complexo sistema por meio de nossas práticas, as quais, neste caso, concernem à pesquisa científica, formamos um novo campo de realidade em que as práticas são inseparáveis dos aspectos sensíveis dessa realidade. [...] É impossível pensar que temos um acesso ilimitado e direto ao sistema do real, portanto, tal acesso é sempre parcial e limitado a partir de nossas próprias práticas (González Rey, 2005, p. 5).
}

A visão imediata da realidade quase sempre é aparente. Buscar a essência, a compreensão mais profunda do real que se pretende conhecer constitui-se em um processo de construção e reconstrução dessa realidade, de apreensão das mediações sociais constitutivas do ser, do sujeito, o que possibilita sair das aparências, do imediato, e ir em busca do processo, do não dito, do sentido é o que caracteriza a pesquisa científica. As visões sociais de mundo e os valores (que fazem parte dela) intervêm também na análise empírica da causalidade, na 
determinação científica dos fatos e de suas conexões assim como na interpretação geral dos resultados das pesquisas e na construção de teorias. Enfim,

\section{[...] é o conjunto do processo de conhecimento científico social desde a formulação das hipóteses até a conclusão teórica, passando pela observação, seleção e estudo dos fatos, que é atravessado, impregnado, 'colorido' por valores, opções ideológicas (ou utópicas) e visões sociais de mundo (Löwy, 1998, p. 203).}

Dentre as correntes teórico-metodológicas que analisam as concepções de mundo e de pesquisa nas ciências humanas, duas podem ser consideradas neste momento: o positivismo analisado por Löwy $(1998$, p. 17) que defende o fato da sociedade ser regida por leis naturais, invariáveis e independentes da vontade e da ação humana. Nessa linha, Durkheim (1858 - 1917) defende a neutralidade axiológica das ciências sociais e Comte (1798 - 1857) desenvolveu suas ideias com base nesse princípio de que os fatos sociais devem ser tratados como coisas, isolados de outras considerações. Esses autores influenciaram as Ciências Sociais no Brasil e, em especial, os cursos de formação de professores, no antigo Curso Normal e nos cursos de Pedagogia e de Sociologia (Ciavatta, 2015).

Outra corrente teórico-metodológica refere-se ao materialismo dialético histórico, cujos expoentes são Marx (1818 - 1883) e Engels (1820 - 1895). Para Marx e Engels, a história é a produção social da existência humana abrangendo o conhecimento, a ciência, a cultura e a educação. A produção do conhecimento fica ancorada nas categorias: dialética, totalidade, contradição, mediação, particularidade, história, ideologia e promove a transformação social como resultado do trabalho dos seres humanos em sociedade. Até o final da ditadura, a pesquisa em educação seguia uma orientação mais positivista, com o uso intenso de dados quantitativos e análises estatísticas. Com o término daquele regime, as pesquisas nas Ciências Sociais e na Educação, gradualmente, foram adotando essas premissas dialéticas do materialismo histórico (Ciavatta, 2015).

Nesta perspectiva, a concepção de trabalho enquanto valor intrínseco de sobrevivência e um princípio de cidadania é fundamental. $O$ trabalho inclui as atividades produtivas e culturais geradas em torno da reprodução da vida. É um universo complexo que à custa de muita simplificação fica focado em formatos históricos como "a profissão, os produtos do trabalho e as atividades laborais" (Ciavatta, 2015, p. 29). As relações entre educação e trabalho e as transformações pelas quais este vêm passando devido a utilização de tecnologias avançadas e as mudanças econômicas e políticas interpostas pela nova ordem internacional constituem-se em desafios para os profissionais da educação.

\section{CONCLUSÃO DO BALANÇO REALIZADO}

O trabalho docente na atualidade insere-se em um contexto de contradições que caracteriza a sociedade brasileira e que conduz a uma situação de precarização de grande parte desses profissionais. Precarização decorrente dos baixos salários, das condições inadequadas dos ambientes de trabalho e da falta de valorização social da profissão. É claro que há exceções. $O$ próprio processo de desenvolvimento socioeconômico que conduziu esses profissionais a essa situação de precariedade pode apontar saídas para uma educação emancipadora. 
A análise do trabalho docente em sua historicidade possibilitou perceber o movimento dialético de (re)construção e de mudança do mesmo e de suas correlações com as dimensões sociais, políticas, econômicas e culturais. A cronologia dos fatos permitiu compreender, explicitar e explicar as mediações que produziram o modo de ser professor e as contradições sociais que afetam essa classe de trabalhadores.

Por outro lado, a pesquisa e a inovação tecnológica apontam alternativas, mas, ficam restritas a um número reduzido da população. De fato, no âmbito da instituição escolar, a socialização e a construção do conhecimento ficam comprometidas pela precariedade das instituições escolares, pelos baixos salários pagos aos professores e pelas condições escassas de vida de grande parte dos alunos, e desse modo, exclui a maioria da população dos benefícios produzidos no contexto da pesquisa e da inovação tecnológica. A crise contemporânea tem contribuído para consolidar uma consciência social alienada e uma prática pedagógica despolitizada, pouco engajada e compromissada com a transformação das condições de vida atuais.

Espera-se que a análise das opções teórico-metodológicas possa colaborar para a compreensão de como ocorre a inserção do indivíduo na sociedade, no grupo e na classe social propiciadas pelo trabalho, tecnologia, inovação e pesquisa. São articulações entre essas e outras esferas que permitem compreender como elas transformam o sujeito em ser social com seus modos de ser, agir, sentir, pensar, imaginar e inovar. Há entre o indivíduo e a sociedade uma relação na qual se incluem e se excluem ao mesmo tempo. A inclusão ocorre porque no fazer individual há sempre colaboração, por mais alheia que seja.

\section{CONSIDERAÇÕES FINAIS}

Nesse processo de construção do indivíduo e do social, a educação realiza um papel fundamental contribuindo no desenvolvimento da cidadania, do profissional e na produção científica, tecnológica e cultural. A educação, de forma decisiva, participa da formação do indivíduo e da coletividade e contribui para a transformação das condições de vida da população quando trabalha os instrumentos que propiciarão os diferentes modos de inserção nos grupos sociais e nas diversas formas de sociabilidade.

A escola está sempre em busca de alternativas para a realização de uma educação de qualidade mesmo em contextos adversos. Nessa perspectiva, a ideia de educação permanente e de formação por meio da ação organizacional vem sendo testada em vários espaços na busca de criar condições para a implantação de novos modelos de práticas docentes. Na troca de experiências podem estar as alternativas para progressivamente criar uma nova cultura focada na lógica do desenvolvimento profissional dos professores e do desenvolvimento organizacional das escolas.

Urge que o desenvolvimento profissional e organizacional, em que os professores integrados em redes de cooperação e colaboração profissional possam refletir na e sobre a prática pedagógica. As investigações sobre as práticas docentes só têm sentido quando envolvem e acontecem com a participação dos professores. É dessa forma que outra cultura profissional 
poderá ser construída a partir dos sistemas e dos saberes tecidos pelos professores em percurso de renovação permanente para (re)criar uma profissão essencialmente reflexiva e científica.

O trabalho docente tem uma relação direta com o processo formativo que, por isso, deve provocar o professor para que ele se assume como sujeito de sua história, em busca de um agir responsável e autônomo perante si e o mundo e seja capaz de um enfrentamento crítico perante os desafios do trabalho docente mesmo em um contexto de adversidades.

\section{REFERÊNCIAS}

Antunes, R. (2018). O privilégio da servidão: o novo proletariado de serviços na era digital. São Paulo: Boitempo.

Basso, I. S.(1998). Significado e sentido do trabalho docente. Cad. CEDES. Vol. 19, n. 44. Campinas, Apr. Recuperado de http://www.scielo.br/scielo.php?script=sci_arttext\&pid=S0101-32621998000100003

Baumgarten, M., Teixeira, A. N. \& Lima, G. (2007). Sociedade e Conhecimento: novas tecnologias e desafios para a produção de conhecimento nas Ciências Sociais. Sociedade e Estado, Brasília, v. 22, n. 2, p. 401 - 433, maio/ago. 2007. Recuperado de http://www.scielo.br/pdf/se/v22n2/06.pdf

Cecílio, S. (2017). Plano de Ensino de Epistemologia e Pesquisa em Educação. Programa de PósGraduação em Educação. Doutorado. Pró-Reitoria de Pós-Graduação, Pesquisa e Extensão. UNIUBE. Uberaba, MG, Impresso.

Charlot, B. (2008). O professor na sociedade contemporânea: um trabalhador da contradição. Revista da FAEEBA. Educação e contemporaneidade. Salvador, v. 17, n.30, p. 17-31, jul./dez.

Ciavatta, M. (2015). O trabalho docente e os caminhos do conhecimento: a historicidade da Educação Profissional. Rio de Janeiro: Lamparina, 124p.

Dusavitskii, A. K. (2014). Educação desenvolvente e a sociedade aberta. Ensino em Re-vista, v. 21, n.1, p.101-110, jan./jun., p. 77-84.

Ens, R. T., Gisi, M. L. \& Eyng, A. M. (2011). Formação de professores: possibilidades e desafios do trabalho docente na contemporaneidade. Rev. Diálogo Educ. Curitiba, v. 11, n. 33, p. 309-329, maio/ago.

Flores, M. A. (2018). O que vale a Educação? Caderno de Apontamentos. Recuperado de https://observador.pt/opiniao/o-que-vale-a-educacao/

Gatti, B. A. (2009). Formação de professores: condições e problemas atuais. Revista Brasileira de Formação de Professores - RBFP. Vol. 1, n.1, p. 90-102, mai.

Giroux, H. A. (1999). Professores como intelectuais transformadores. In: Os professores como intelectuais: rumo a uma pedagogia crítica da aprendizagem. Porto Alegre: Artes Médicas, p. 156-178.

González Rey, F. (2005). Pesquisa qualitativa e subjetiva: os processos de construção da informação. Tradução: Marcel Aristides Ferrada Silva. São Paulo: Pioneira Thomson Learning, p. 5. 
Löwy, M. (1998). As aventuras de Karl Marx contra o Barão de Münchhausen: marxismo e positivismo na sociologia do conhecimento. 6. ed. São Paulo: Cortez, 203p.

Manfredi, S. M. (2003). Educação profissional no Brasil. São Paulo: Cortez.

Macedo, J. M. de\& Lima, M. M.(2017). Fundamentos teóricos e metodológicos da precarização do trabalho docente. Revista trabalho, política e sociedade. v. 2, n. 3. Recuperado de http://www.ufrrj.br/SEER/index.php?journal=RTPS\&page=article\&op=view\&path\%5B\%5D=36 80

Saviani, D. (2002a). O trabalho como princípio educativo frente às novas tecnologias. In: Ferretti, Celso João et al (Orgs.). Novas tecnologias, trabalho e educação: um debate multidisciplinar. 7. edição. Petrópolis, RJ: Vozes, p. 151-168.

. (2002b). Transformações do capitalismo, do mundo do trabalho e da educação. In: Lombardi, J. C.; Saviani, D.; Sanfelice, J. L. (Orgs.). Capitalismo, Trabalho e Educação. Campinas, SP: Cortez, p. 13-24.

. (2013). História das ideias pedagógicas no Brasil. 4. ed. Campinas, SP: Autores Associados. (Coleção memória da educação).

Silva, K. N. P. \& Silva, J. A. A. (2017). Trabalho docente e educação integrada nas escolas técnicas estaduais de Pernambuco. Educar em Revista, Curitiba, Brasil, n. 65, p. 237-247, jul./set. Recuperado de http://www.scielo.br/pdf/er/n65/0104-4060-er-65-00237.pdf

Souza K. L. et al, (2018). Cadernetas de saúde e trabalho: diários de professores de universidade pública. Cad. Saúde Pública 2018; 34(3): e00037317. Recuperado de http://www.scielo.br/pdf/csp/v34n3/1678-4464-csp-34-03-e00037317.pdf

Zeichner, K. (1998). Para além da divisão entre professor-pesquisador e pesquisador acadêmico. In: Geraldi, C. M. G.; Fiorentini, D. (Org.). Cartografias do trabalho docente: professor (a) pesquisador (a). Campinas. SP: Mercado de Letras: Associação de Leitura do Brasil - ALB, p. 207-236. 